\title{
USE OF THE FINITE ELEMENTS METHOD IN THE ANALYSIS \\ OF LOAD OF POLYETHYLENE INSERTS OF KNEE JOINT ENDOPROSTHESIS
}

\author{
Marcin Nabrdalik \\ Institute of Mechanical Technology, Czestochowa University of Technology \\ Czestochowa, Poland \\ marcin@iop.pcz.pl
}

\begin{abstract}
The paper presents the numerical analysis of stress occurring in the most wearable parts of knee joint endoprostheses. That applies to the pair: sled - spherical insert. The Finite Elements Method makes it possible to calculate the stress in particular elements of the tested model. The interaction between the two parts of endoprosthesis takes place on a comparatively small contact surface.
\end{abstract}

Keywords: contact stress, FEM, endoprosthesis

The Finite Elements Method (FEM) makes it possible to conduct a wide range of numerical analyses of strength with the usage of virtual models. As the method provides much more precise results than any simplified analytic calculations, it is commonly used in engineering calculations. Additionally, it is cheaper and easier in application than other experimental methods and furthermore faster in obtaining the results, which is critical in any real conditions. With FEM it is possible to define the values of stress in friction nodes of knee joint endoprostheses, regardless of the shape of sleds or polyethylene inserts, subjected to different loads. Therefore the stress and strain values distribution is clear and obtained quickly, even if there are many similar models of endoprostheses considered, without the necessity to bear the costs of constructing each of them separately; furthermore, it can quickly optimize construction.

\section{Polyethylene inserts applied in knee joint endoprostheses}

Properly adjusted joints' elements, like sleds and polyethylene inserts, can significantly reduce the problem of high contact stress in the area where the components are subjected to friction and wear. As polyethylene has lower strength values than titanium alloy, the shape of the inserts must ensure the reduction of wear. However, the perfect shape is still being sought and worked on, as the geometry of polyethylene insert must be optimal in order to prolong the time between implantation and the next surgery. 
There are two kinds of currently used inserts:

- flat,

- spherical.

Figure 1 presents both geometrical solutions of polyethylene inserts.

a)

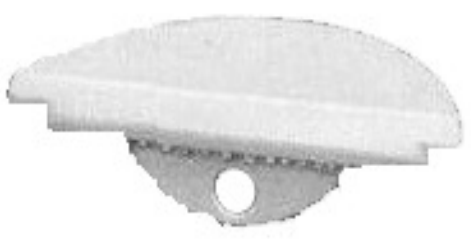

b)

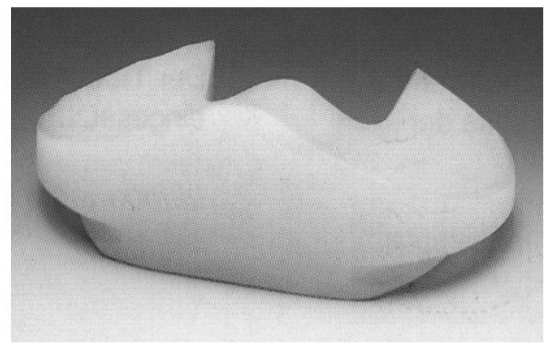

Fig. 1. Polyethylene inserts: a) flat, b) spherical

It is still widely discussed which would be the best shape for polyethylene inserts used in endoprostheses, as far as functional, assembly and strength features are concerned, as those are critical for the endoprosthesis durability [1,2]. Some constructors and medical doctors support the option of flat inserts, as those allow some surgical mistakes during implantation of both elements of endoprosthesis. Spherical inserts adherents emphasise that thanks to this shape, the range of unit pressure is acceptably low; but they also admit that implanting this kind of insert requires accuracy and precision [3].

\section{Geometrical model of knee joint endoprosthesis}

Considering a very simple wear model [4-6], a numerical analysis of tribological phenomena taking place in artificial joints reveals the wear process of UHMWPE polyethylene insert, used in knee joint endoprostheses.

If we want to analyse contact strength or stress occuring in polyethylene insert, it is enough to construct a simplified model consisting of a metal sled and a polyethylene insert, which will let us settle the required values and analyse the phenomena occurring in the friction point of endoprosthesis.

The analysis was carried out in ADINA System 7.5.1. based on the Finite Elements Method. The finite elements mesh was built of 3600 cube-shaped elements of 3D Solid type and 4312 nodes. The model presented in the paper consists of the elements respective to all parts of endoprosthesis: thigh, tibia, and polyethylene insert. Additionally, there numerical calculations are presented defining the influence of the implant geometry on the stress pattern in the contact area of the cases: sled with the cross-section radius $17 \mathrm{~mm}$ - spherical insert and sled with the cross-section radius $27 \mathrm{~mm}$ - spherical insert. 
The geometrical model of sled - spherical insert subjected to load and finite elements mesh is shown in Figure 2. Such a discrete model of sled and insert was used to simulate the performance of polyethylene inserts subjected to mechanical loads.

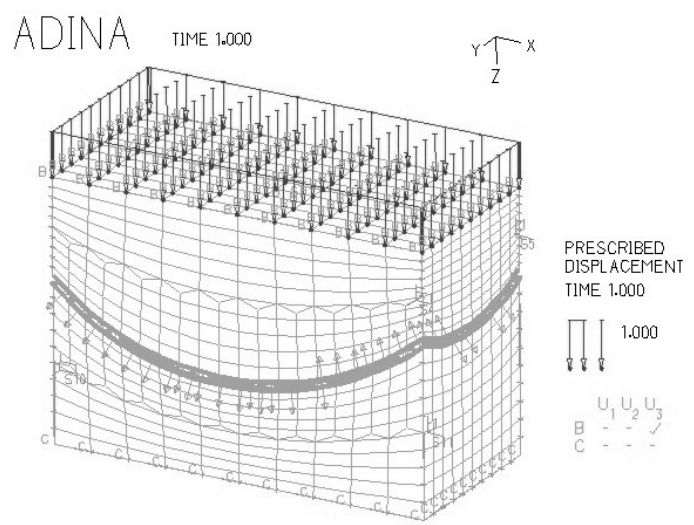

Fig. 2. Geometrical model of the set sled - spherical polyethylene insert. Finite elements mesh, load, degrees of freedom and contact area. General view

\subsection{Numerical calculations data}

Stress distribution in the contact area, where the sleds are pressed onto the inserts, are based on the assumptions:

- the contact area is continuous and relatively smaller than other cooperating elements,

- implemented load is close and relative to the one occurring in the real knee joint,

- both contacted parts are made of isotropic material and obey Hook's law.

\subsection{Material data. The load model}

All calculations were carried out considering spherical inserts, made of medical polyethylene of higher density (UHMWPE) and $8 \mathrm{~mm}$ thick.

Boundary conditions settled for the calculations represent mechanical features of endoprostheses' elements as well as mechanical load distribution and values. It was assumed that all materials used for models (medical titanium alloy Ti6Al4V, polyethylene UHMWPE) are linear-elastic and isotropic with constant mechanical features.

Mechanical features and density of materials used for endoprostheses:

Ti6Al4V: $\mathrm{E}=1.1 \cdot 10^{5} \mathrm{MPa}$; Poisson's coefficient $v=0.3$,

UHMWPE: $\mathrm{E}=1000 \mathrm{MPa}$; Poisson's coefficient $v=0.4$. 
The calculations apply to standard and simplified model of the pair subjected to load put onto the upper surface of endoprosthesis sled.

\section{Stress analysis for "sled $17 \mathrm{~mm}$ - spherical insert" and "sled $27 \mathrm{~mm}$ - spherical insert" in the knee joint endoprosthesis}

It is quite common that polyethylene inserts are more worn than metal sleds. This type of wear occurs where the stress is concentrated in the real contact area.

The following values were taken for the analysis $(1)[7,8]$ :

$$
\begin{aligned}
& c=0.721 \sqrt[3]{P \frac{D_{1} D_{2}}{D_{1}-D_{2}}\left(\frac{1-v_{1}^{2}}{E_{1}}+\frac{1-v_{2}^{2}}{E_{2}}\right)^{2}} \\
& q_{o}=0.918 \sqrt[3]{P \frac{\left(\frac{D_{1}-D_{2}}{D_{1} D_{2}}\right)^{2}}{\left(\frac{1-v_{1}^{2}}{E_{1}}+\frac{1-v_{2}^{2}}{E_{2}}\right)^{2}}}
\end{aligned}
$$

where:

$P$ - total pressure between the 2 elements,

$q_{o}$ - highest compressive stress,

$c$ - circular contact radius,

$v$ - Poisson's coefficient; 1 and 2 - contacting elements,

$E$ - Young modulus,

$D$ - contacting element's diameter in the contact point.

Figure 3 presents an example of stress distribution $q_{o}(x, y)$ in the contact area marked by ellipse.

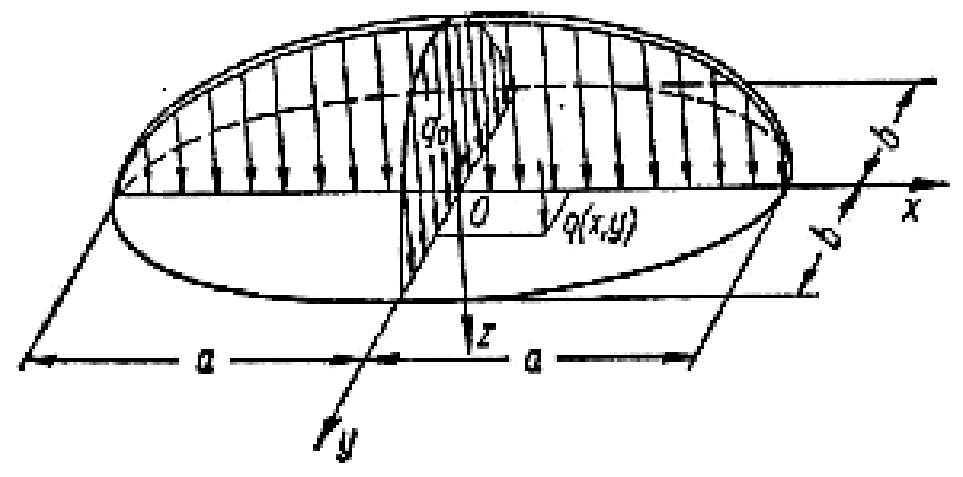

Fig. 3. Stress distribution in the elliptic contact area [7, 8] 
According to Huber's theory, the reduced stress in the points on the axis connecting the curves' centres of the contacting elements, can be presented by the pattern (2) [8]:

$$
\sigma_{\text {red }}=q_{o}\left[\frac{3}{2} \frac{a^{2}}{a^{2}+z^{2}}-(1-v)\left(1+\frac{z}{a} \operatorname{arctg} \frac{a}{z}\right)\right]
$$

where:

$a$ - contact radius,

$z$ - distance between considered point and elements' contact surface,

$v$ - Poisson's coefficient.

Differentiation of the pattern (2) according to $z$, provides the extremum, from which the only real radix is

$$
z_{\sigma \max }=0.481 a
$$

The evaluation of the achieved results was based on stress pattern in the section of particular models of endoprostheses. The calculations were carried out for total knee joint endoprosthesis. The most significant results observed are the reduced contact stresses in particular types of polyethylene inserts, due to the weakest kinematic point of endoprostheses, which is UHMWPE polyethylene.

The results of numerical calculations for particular geometrical models are presented in Figures 4-7.

Due to large bearing surface, low values of unit pressure occur in the contact area of both elements of endoprostheses. Pressure distribution is uniform because of the surface contact.

In knee joint endoprostheses consisting of spherical inserts durability time is longer, wear proceeds slower than in those with flat inserts.

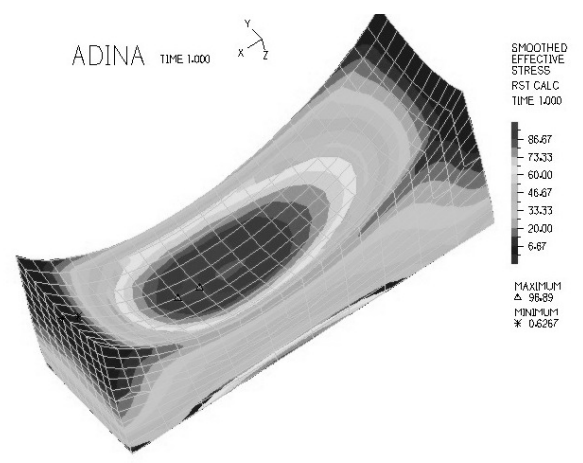

Fig. 4. Contact stress pattern in the spherical polyethylene insert. General view of the model. The insert is $8 \mathrm{~mm}$ thick and cooperates with the sled of $17 \mathrm{~mm}$ radius. Load $1500 \mathrm{~N}$ 


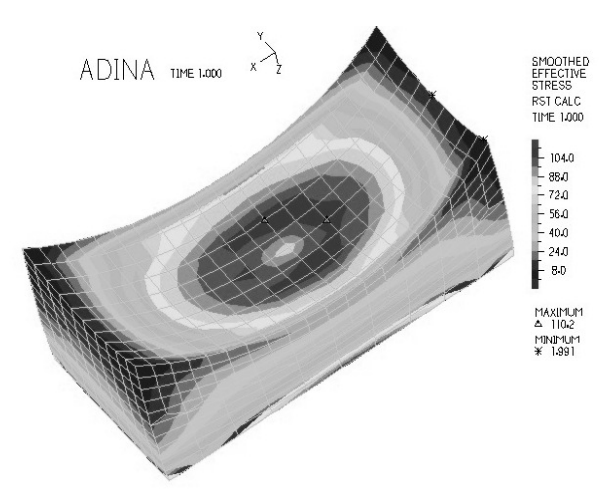

Fig. 5. Contact stress pattern in the spherical polyethylene insert. General view of the model. The insert is $8 \mathrm{~mm}$ thick and cooperates with the sled of $27 \mathrm{~mm}$ radius. Load $1500 \mathrm{~N}$

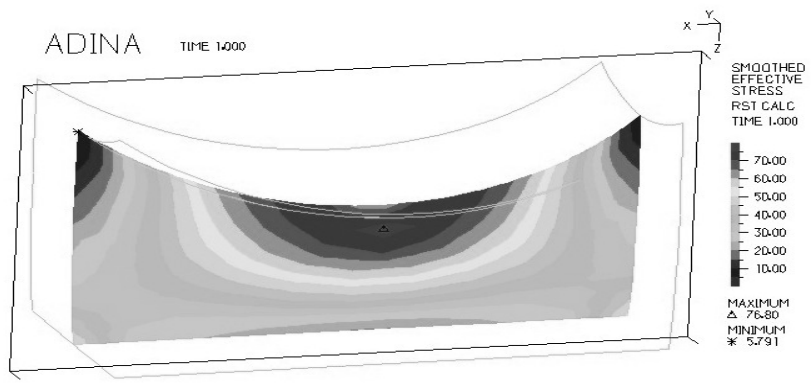

Fig. 6. Huber-Mises's reduced stress distribution occurring in spherical polyethylene insert. Subsurface stress. Cross-section of the model. Spherical insert is $8 \mathrm{~mm}$ thick cooperating with sled of $27 \mathrm{~mm}$ radius. Load $1500 \mathrm{~N}$

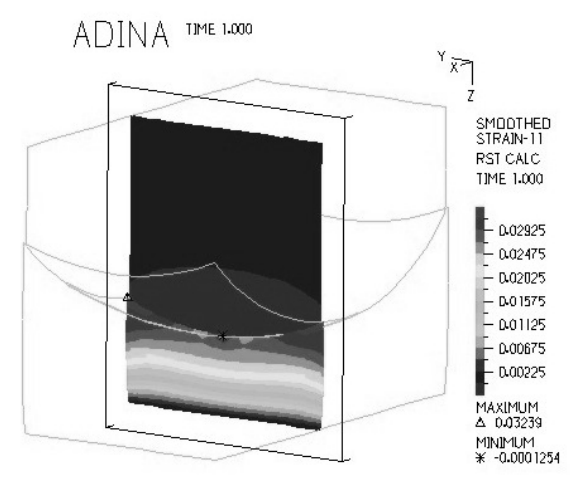

Fig. 7. Material strain distribution occurring in sub-surfaces of spherical polyethylene insert cooperating with metal sled. Cross-section of the model. Sled of cross-section $27 \mathrm{~mm}$ radius. Load $1500 \mathrm{~N}$ 


\section{Conclusions drawn from the numerical simulations on knee joint endoprosthesis concerning strain distribution in the IMPLANT}

1. Lower values of contact stress can be obtained by proper adjustment of cooperating elements and substituting linear contact with the surface contact.

2. When spherical insert cooperates with sled of cross-section radius $27 \mathrm{~mm}$, the pressure values are lower than in case of sled of cross-section radius $17 \mathrm{~mm}$. Due to that the insert's strength is higher but it decreases the range of movements of the whole joint.

3. Conducted tests prove that if spherical polyethylene insert is used, the stress is lower and distributed evenly; that confirmed the results of empirical tests carried out on knee joint endoprostheses simulator.

\section{References}

[1] Będziński R., Biomechanika inżynierska, Oficyna Wydawnicza Politechniki Wrocławskiej, Wrocław 1997.

[2] Gierzyńska-Dolna M., Biotribologia, Wydawnictwo Politechniki Częstochowskiej, Częstochowa 2002.

[3] Ungethum M., Winkler-Gniewek W., Tribologie in der Medizin, Tribologia und Schmierungstechnik 1990, 5, 268-277.

[4] Gierzyńska-Dolna M., Kubacki J., Wieczorek A., Tatar K., Mechanizm zużycia endoprotezy saneczkowej stawu kolanowego, Biology of Sport 1998, 112-119.

[5] Krzesiński G., Zagrajek T., Modelowanie własności mechanicznych kości, Biology of Sport $1998,15,8$.

[6] Marciniak J., Biomateriały, Wydawnictwo Politechniki Śląskiej, Gliwice 2002.

[7] Zakrzewski M., Zawadzki J., Wytrzymałość materiałów, Wrocław 1975.

[8] Zienkiewicz O.C., Metoda elementów skończonych, Wyd. Arkady, 1972. 